TITLE:

\title{
Effects of repeated treatment on the properties of rice stem extract using subcritical water, ethanol, and their mixture
}

\section{$\operatorname{AUTHOR(S):~}$}

Tangkhavanich, Boonnakhom; Kobayashi, Takashi; Adachi, Shuji

\section{CITATION:}

Tangkhavanich, Boonnakhom ...[et al]. Effects of repeated treatment on the properties of rice stem extract using subcritical water, ethanol, and their mixture. Journal of Industrial and Engineering Chemistry 2014, $20(4): 2610-2614$

\section{ISSUE DATE:}

2014-07-25

URL:

http://hdl.handle.net/2433/187804

\section{RIGHT:}

(C) 2013 The Korean Society of Industrial and Engineering Chemistry. Published by Elsevier B.V.; This is not the published version. Please cite only the published version.; この論文は 出版社版でありません。引用の際には出版社版をご確認ご利用ください。 
Running title: Properties of rice stem extract

\title{
Effects of repeated treatment on the properties of rice stem extract using subcritical water, ethanol, and their mixture
}

\author{
Boonnakhom TANGKHAVANICH, Takashi KOBAYASHI, Shuji ADACHI ${ }^{\dagger}$ \\ Division of Food Science and Biotechnology, Graduate School of Agriculture, Kyoto University, \\ Sakyo-ku, Kyoto, 606-8502, Japan
}

\begin{abstract}
Rice stem was repeatedly treated 3 times with subcritical water, ethanol, and $75 \%(\mathrm{v} / \mathrm{v})$ ethanol in different orders at $230^{\circ} \mathrm{C}$ for $5 \mathrm{~min}$ during each treatment step to extract its constituents. The obtained extracts were subjected to an analysis of their yield, carbohydrate content, phenolic content, radical scavenging ability, color, and UV absorption spectra. The highest total carbohydrate and phenolic contents were obtained by treatment with subcritical water, and with subcritical ethanol after pre-treatment with subcritical water, respectively. However, the extract with the highest radical scavenging ability was obtained by treatment with subcritical $75 \%(\mathrm{v} / \mathrm{v})$ ethanol as the 1 st treatment.
\end{abstract}

Keywords: rice straw, 3-step extraction, subcritical ethanol, subcritical water

\section{Introduction}

As an agricultural waste, rice straw has been typically disposed of by open-field burning or soil incorporation. These two methods of disposal would cause environmental pollution $[1,2]$. One of the potential uses of rice stem is a source for extracting carbohydrate and phenolic substances from its main constitutions; i.e., cellulose, hemicelluloses, and lignin [3]. Cellulose and lignin have a low solubility at ambient temperature in water due to the strong hydrogen bonds between the glucose molecules of cellulose and the covalent bonds in lignin [4]

Subcritical fluid extraction is also known as pressurized liquid extraction or accelerated solvent extraction. It is an extraction method, which uses extractants at elevated temperature, while applying high pressure to maintain their liquid state. Under the subcritical state, the surface tension and viscosity of the extractants decrease with the increasing temperature. The decrease in the surface tension would increase the penetration of the extractant into the stem matrix and enhance the solubility of the constituents in the extractant [5]. When water, one of the safest solvents, is employed as the extractant, the specific name of the subcritical water extraction or hot compressed water extraction is used. Under subcritical conditions, the ion product of water increases to over $1 \times 103$ fold greater than that of water at room temperature [6]. Moreover, the dielectric constant of subcritical water decreases to those of polar organic solvents with the increasing temperature [7], and it is further reduced by adding an organic solvent, such as ethanol [8]. The change in the dielectric constant of the extractant would change the solubility of the extracted substances, which resulted in different compositions being dissolved. Thus, employing a subcritical treatment using water, ethanol, and $75 \%(\mathrm{v} / \mathrm{v})$ ethanol on the same sample would yield different extract compositions.

The subcritical aqueous ethanol treatment has been extensively used to extract carbohydrates and phenolic compounds [9-12]. However, the role of subcritical water and ethanol has not been clearly understood. Therefore, the aim of this study was to use a repeated treatment using subcritical water, ethanol, and $75 \%(\mathrm{v} / \mathrm{v})$ ethanol in different orders in order to investigate the role of water and ethanol in extracting carbohydrate and phenolic compounds. Additionally, the yield and UV spectra of the rice stem extract were measured, and the relationship between the color and radical scavenging ability of the extract was also established.

\section{Experimental}

\subsection{Materials}

A cultivated rice straw (Oryza sativa) sample from Hyogo Prefecture, Japan, was sun-dried and then kept at $4^{\circ} \mathrm{C}$ in a storage room. The stem was separated from the leaves and cut into 1-cm long pieces before the experiments. L-Ascorbic acid (purity $>99.5 \%$ ) was purchased from Nacalai Tesque (Kyoto, Japan). Gallic acid was from Sigma-Aldrich Japan (Tokyo, Japan). The Folin-Ciocalteu reagent was from ICN Biochemicals (Aurora, OH, USA). 1,1-Diphenyl-2picrylhydrazyl (DPPH), and all other chemicals of reagent grade were from Wako Pure Chemical Industries (Osaka, Japan). Distilled water was used in all the experiments.

\subsection{Preparation of extract}

Rice stem was repeatedly treated 3 times using subcritical water, ethanol, and $75 \%(\mathrm{v} / \mathrm{v})$ ethanol in different orders. The experimental runs are expressed in Table 1 . A The extractions were done in a $117-\mathrm{mL}$ SUS-316 stainless steel vessel (30 $\mathrm{mm}$ i.d. $\times 165.5 \mathrm{~mm}$ ) assembled by Taiatsu Techno (Osaka, Japan). A 5-g sample of rice stem and $55 \mathrm{~mL}$ of extractant were added to the vessel, then it was tightly closed. The vessel was heated to $230^{\circ} \mathrm{C}$ by a mantle heater ( $200 \mathrm{~W}$, Sogo Laboratory Glass Works, Kyoto, Japan). A thermocouple was inserted into a tube installed in the vessel for measuring its internal temperature. Excluding the heat-up period $\left(7.2^{\circ} \mathrm{C} / \mathrm{min}\right)$, the desired temperature was maintained for 5 min. From the calculation of the vapour pressure and the expansion of air in the head space, the pressure inside the vessel was estimated to be 0.33 to $3.6 \mathrm{MPa}$ at $120^{\circ} \mathrm{C}$ to $260^{\circ} \mathrm{C}$. Moreover, the critical temperatures of ethanol and acetone are $241^{\circ} \mathrm{C}$ and $235^{\circ} \mathrm{C}$, respectively $[13,14]$. The gas phase of the extractant during the treatment at $230^{\circ} \mathrm{C}$ would provide the sufficient pressure for the extractants to maintain their liquid state. The vessel was then put in an ice bath for immediate cool down to room temperature after the treatment to stop the extraction. The crude extracts were Table 1 Treatment run

\begin{tabular}{clll}
\hline Run & 1st treatment & 2nd treatment & 3rd treatment \\
1 & Ethanol & 75\%Ethanol & Water \\
2 & Ethanol & Water & 75\%Ethanol \\
3 & Water & 75\%Ethanol & Ethanol \\
4 & Water & Ethanol & 75\%Ethanol \\
5 & $75 \%$ Ethanol & Ethanol & Water \\
6 & $75 \%$ Ethanol & Water & Ethanol \\
\hline
\end{tabular}


filtered through an Advantec filter paper (No. 2, Toyo Roshi, Tokyo, Japan) to obtain the clarified extracts. Until used for the analysis, the extracts were stored in a refrigerator at $4^{\circ} \mathrm{C}$. The treated stem was dried in a hot-air oven (DN 400, Yamato Scientific, Tokyo, Japan) at $105^{\circ} \mathrm{C}$ for $3 \mathrm{~h}$ before the repeated treatment.

\subsection{Yield of extract}

A 15-mL sample of the rice stem extract was freeze-dried using an FDU-1200 freeze-dryer (Tokyo Rikakikai, Tokyo, Japan), and then placed in a hot-air oven at $105^{\circ} \mathrm{C}$ for $3 \mathrm{~h}$. The extract yield was calculated by dividing the weight of the dry solid extract by that of the dry rice stem.

\subsection{Total carbohydrate content}

The carbohydrate content of the extract was measured by the phenol-sulfuric acid method with some modifications [15]. To a test tube containing $1 \mathrm{~mL}$ of the appropriately diluted extract was added a $25-\mu \mathrm{L}$ aliquot of an $80 \%$ (w/w) aqueous phenol solution and $2.5 \mathrm{~mL}$ of sulfuric acid. After storage at room temperature for $10 \mathrm{~min}$, the test tube was put in a $30^{\circ} \mathrm{C}$ water bath for another $10 \mathrm{~min}$. The absorbance at $490 \mathrm{~nm}$ was measured using an UV-1200 spectrophotometer (Shimadzu, Kyoto, Japan). The total carbohydrate content was calculated using glucose as the standard.

\subsection{Total phenolic content}

The $100-\mu \mathrm{L}$ diluted straw extract was added to a test tube with $400 \mu \mathrm{L}$ of freshly prepared Folin-Ciocalteu reagent and $1 \mathrm{~mL}$ of $75 \mathrm{~g} / \mathrm{L}$ sodium carbonate $[16,17]$. The volume of the mixture was adjusted to $5 \mathrm{~mL}$ by adding distilled water, and then the test tube was placed in the dark at room temperature for $2 \mathrm{~h}$ to complete the reaction. The absorbance at $765 \mathrm{~nm}$ was measured. The amount of phenolic compounds in the extracts was compared with gallic acid and was expressed as the gallic acid equivalent (mg-gallic acid/g-straw).

\subsection{Radical scavenging ability}

The 4-mL diluted rice straw extract and $1 \mathrm{~mL}$ of $0.5 \mathrm{mmol} / \mathrm{L}$ DPPH in ethanol were added to a black tube, which prevents a reaction with light. After agitation, the black tube was allowed to stand at room temperature for $20 \mathrm{~min}$. The remaining radical quantity was calculated based on the absorbance measured at $516 \mathrm{~nm}$. The percentage of the radical scavenging ability was computed as follows [18]:

Radical scavenging ability (\%)

$$
=(\mathrm{A}-\mathrm{B}+\mathrm{C}) / \mathrm{A} \times 100
$$

where $A$ is the initial absorbance of the DPPH solution, $B$ is the absorbance of the mixture of the sample and DPPH solution, and $\mathrm{C}$ is the absorbance of the diluted sample without the DPPH solution. The radical scavenging ability is defined as the amount of the extract necessary to reduce the DPPH concentration by $50 \%$. It was compared with L-ascorbic acid (VC) and expressed in mmol-VC/g-straw.

\subsection{Color measurement}

Colors of the rice stem extracts were measured using an NF 333 colorimeter (Nippon Denshoku Industries, Tokyo, Japan). The $0.5-\mathrm{mL}$ stem extracts were added to a quartz cuvette $(10 \times 10 \times 43 \mathrm{~mm})$. The white screen, which was used to reflect light back to its source, was immersed into the liquid to attain a height of $5 \mathrm{~mm}$ above the cuvette bottom. The loaded cuvette was then placed in an opaque measurement chamber. The measured color was reported using the CIE color system of L* (lightness), $\mathrm{a}^{*}$ (redness), and b* (yellowness).

\subsection{UV absorption spectra}

The stem extracts were diluted with distilled water to acquire an absorbance of less than unity for the UV measurement. The absorbance was then measured from 200 to $350 \mathrm{~nm}$ using a UV-1200 spectrophotometer.

\subsection{Statistical analysis}

All the experiments were done in triplicate. The obtained results were analyzed using Microsoft ${ }^{\circledR}$ Excel 2010 with a one-way analysis of variance (ANOVA).

\section{Results and Discussion}

3.1. Effects of the repeated treatment on the yield and total carbohydrate content

Figure 1 shows the relationship between the yield and total carbohydrate content of the rice stem. The yield and carbohydrate content of the extracts obtained from the 1st treatment showed a strong correlation $(R=0.91)$. The high correlation between total carbohydrate content and yield in the 1st treatment would be due to the fact that rice stem consists of approximately $24 \%$ hemicellulose, the main extractable carbohydrate [2]. Their correlations decreased with more repeated treatments: $R=0.74$ and 0.69 for the 2 nd and 3rd treatments, respectively. The decrease in the correlation might be due to the decrease in the carbohydrate content in the stem sample resulting from the repeated treatment.

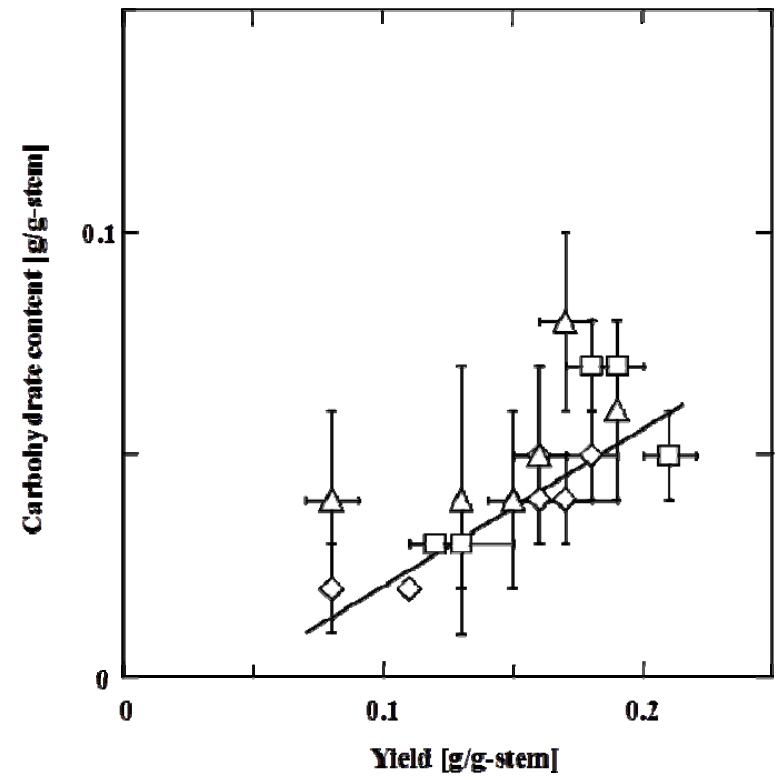

Fig. 1 Relationship between the yield and carbohydrate content of the rice stem extracts obtained from 1 st $(\diamond)$, 2nd $(\square)$, and 3rd $(\triangle)$ treatment. The line indicates the relationship obtained from the 1st extraction.

The yield and total carbohydrate content of the stem extracts obtained using subcritical water and $75 \%(\mathrm{v} / \mathrm{v})$ ethanol for the different treatment steps were not statistically different $(p<0.05)$. For the extracts obtained using the subcritical ethanol, the yield and total carbohydrate content were affected by the sequence of the extraction, i.e., the yield and total carbohydrate content increased when subcritical ethanol was employed after the subcritical water treatment. Although the pre-treatment with subcritical water would loosen the cell wall structure of the rice stem due to the hydrolysis of hemicellulose and amorphous part of cellulose, ethanol alone lacks in such abilities. The hydrolysis of the amorphous part of the cellulose opened the cellulose surface 
cracks [19]. This would facilitate the extraction by subcritical ethanol in the following step. The yield and total carbohydrate content of the extracts obtained using the subcritical ethanol were usually inferior to those obtained using subcritical water and $75 \%(\mathrm{v} / \mathrm{v})$ ethanol. This would suggest that water, which has higher polarity than ethanol $[20,21]$, would be the better solvent for extracting carbohydrates from the rice stem.

\subsection{UV absorption spectra}

The different UV absorption spectral patterns of the extracts obtained using the different extractants suggest different chemical compounds (Fig. 2). The extracts obtained using subcritical water had an absorption maximum at ca. $280 \mathrm{~nm}$ and a shoulder at ca. $220 \mathrm{~nm}$, while those of the extracts obtained using subcritical ethanol and $75 \%(\mathrm{v} / \mathrm{v})$ ethanol showed a plateau around $240-260 \mathrm{~nm}$. The absorbance at 280 $\mathrm{nm}$ would suggest the presence of various phenolic compounds, i.e., phenol acids and flavonoids [22-24]. The non-lignin compounds, e.g., the decomposition products of the carbohydrates and other extractives, would be suggested by the absorbance from 200 to $250 \mathrm{~nm}$ [4].

The absorption spectra of the extracts obtained using the same extractants in the different repeated treatments showed different absorbances. The highest absorbance of the extracts obtained using the subcritical water and ethanol were those of the extracts from the 2nd treatment of runs 2 (Fig. 2a, 4) and 4 (Fig. 2b, 2), respectively. Both the subcritical water and ethanol have been reported to be able to partially hydrolyze/alcoholyze or decompose hemicellulose, lignin, and cellulose $[2,19,25]$. The hydrolysis and decomposition of the primitive cell wall structure would allow the extractant in the following treatment to extract more substances, and consequently, increase the absorbance. The highest absorbance of the extract obtained using the subcritical $75 \%$ $(\mathrm{v} / \mathrm{v})$ ethanol was that of the extract obtained from the 1st treatment (runs 5, 6 in Fig. 2c, 1). This implies that the subcritical $75 \%(v / v)$ ethanol does not require a pre-treatment to enhance its extraction efficiency.

The extracts obtained using the subcritical ethanol in runs 3 , 5, and 6, (Fig. 2b, 3; Fig. 2c, 3; Fig. 2c, 5) and subcritical $75 \%(\mathrm{v} / \mathrm{v})$ ethanol in runs 1, 2, and 4 (Fig. 2a, 3; Fig. 2a, 5; Fig. 2b, 5) showed almost the same UV spectral patterns. They were extracts obtained from the rice stem previously treated with subcritical $75 \%(\mathrm{v} / \mathrm{v})$ ethanol or ethanol in either the 1st or 2nd treatment. This means that subcritical ethanol and $75 \%(\mathrm{v} / \mathrm{v})$ ethanol extracted similar compounds, which reduced the amount of extractable compounds in the following repeated treatment. Therefore, similar UV absorption spectra were obtained.

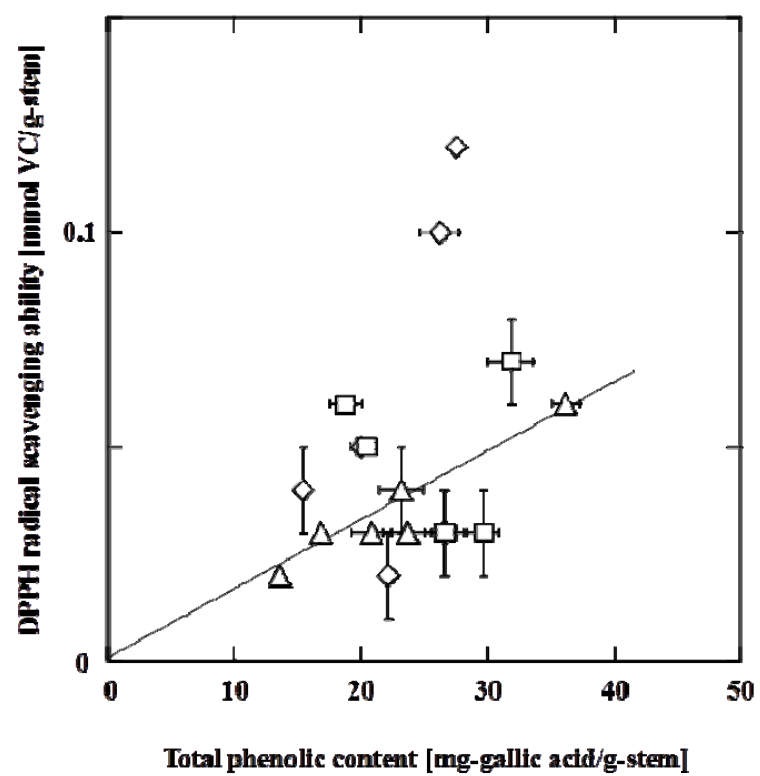

Fig. 3 Relationship between the phenolic content and DPPH radical scavenging ability of the rice stem extracts from 1st $(\diamond)$, 2nd $(\square)$, and 3rd $(\triangle)$ treatments. The line indicates the relationship obtained from the 3rd extraction.

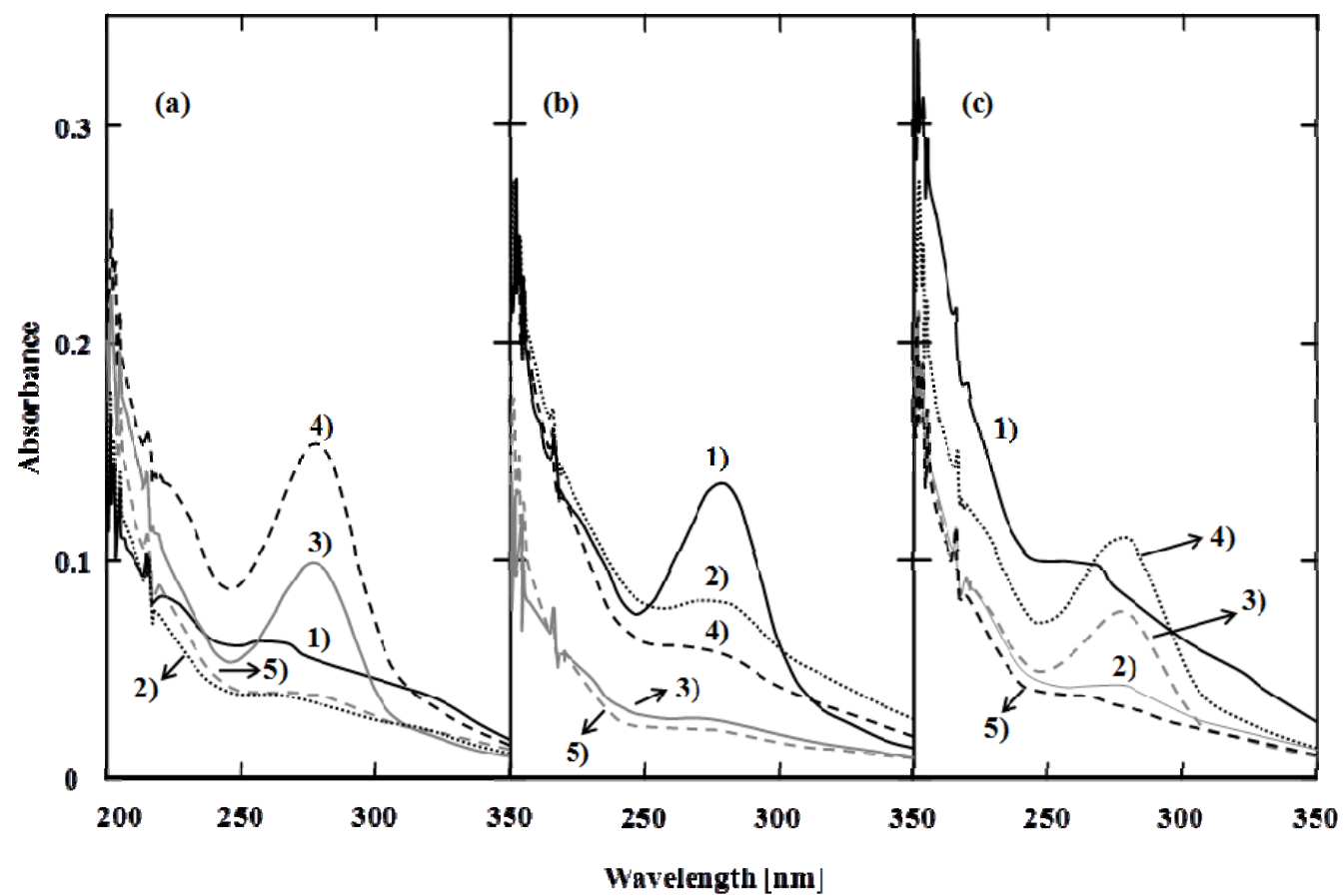

Fig. 2 UV-Vis spectra of the rice stem extracts obtained after treated with (a, 1) 1st treatment of runs 1 and 2, (a, 2) 2nd treatment of run 1, (a, 3) 3rd treatment of run 1, $(\mathrm{a}, 4)$ 2nd treatment of run 2, $(\mathrm{a}, 5)$ 3rd treatment of run 2, (b, 1) 1st treatment of run 3 and 4, (b, 2) 2nd treatment of run 3, (b, 3) 3rd treatment of run 3, (b, 4) 2nd treatment of run 4, (b, 5) 3rd treatment of run 4, (c, 1) 1st treatment of run 5 and 6, (c, 2) 2nd treatment of run 5, (c, 3) 3rd treatment of run 5, (c, 4) 2nd treatment of run 6 , and (c, 5) 3rd treatment of run 6 . The absorbance was from 103 fold diluted rice stem extracts. 
3.3. Effects of the repeated treatment on the total phenolic content and DPPH radical scavenging ability

The phenolic content of the extracts is shown in Fig. 3 together with the DPPH radical scavenging ability. Similar to the UV spectra results, the phenolic contents of the extracts obtained using subcritical water and ethanol increased when they were subsequently used (runs 2 and 4). The highest phenolic content was achieved in the 2nd treatment of run 4 . The increase in total phenolic content in the 2nd treatment by subcritical ethanol might be due to the decomposition of the cellular structure occurring during the 1st treatment by subcritical water $[11,26,27]$. This hypothesis permitted subcritical ethanol to easily access the inner phenolic compounds in the 2nd treatment. As a result, the total phenolic contents became lower in the 3rd treatment. These results may suggest that the treatment might be applicable to the repeated extraction process with stepwise increase of ethanol content in subcritical fluid. During the treatment, the cellular structure would be decomposed by subcritical water followed by the effective extraction of the phenolic compounds by subcritical ethanol.

In our previous study, the DPPH radical scavenging ability of the rice stem extracts were related to the phenolic content of the extract [28]. In Fig. 3, the extracts obtained from the 3rd treatment showed a strong linear relation between the phenolic compound and DPPH radical scavenging ability $(\mathrm{R} 2=0.97)$. The reason behind this strong correlation could be that the compounds responsible for the DPPH radical scavenging ability in the extract obtained by treating with subcritical ethanol and $75 \%$ (v/v) ethanol in the 3rd treatment may be of the same origin, which was explained by their similar UV absorption spectral patterns as shown in Fig. 2.

\subsection{Effect of the repeated treatment on the color of the} extracts

The rice stem extracts obtained using the subcritical water were yellow, while the color of the extracts obtained using the subcritical ethanol and $75 \%(\mathrm{v} / \mathrm{v})$ ethanol were red and black, respectively. Figure 4 shows the relationships of the redness $\left(a^{*}\right)$ and yellowness $\left(b^{*}\right)$ to the lightness $\left(\mathrm{L}^{*}\right)$ of the

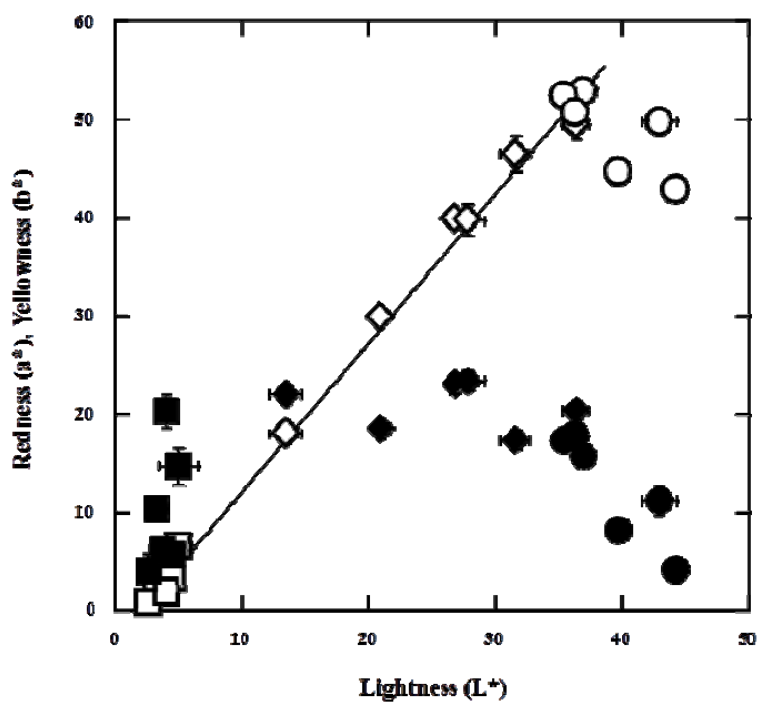

Fig. 4 Relationship between the yellowness (open symbols), redness (closed symbols), and lightness of the rice stem extracts obtained using subcritical water $(\triangle)$, ethanol $(\diamond)$, and $75 \%(\mathrm{v} / \mathrm{v})$ ethanol $(\square)$. The line indicates the relationship between the yellowness and lightness of the extracts.

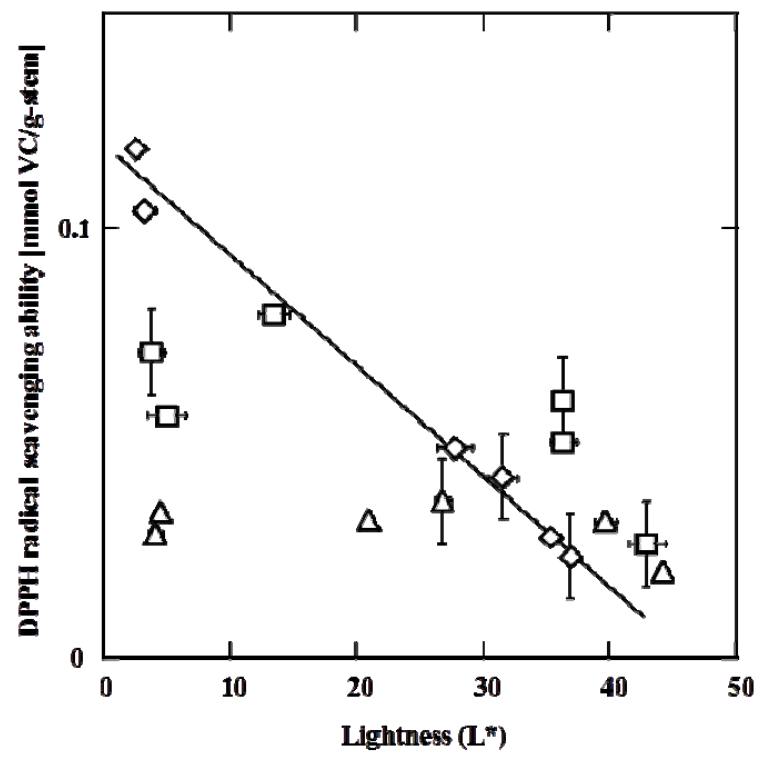

Fig. 5 Relationship between the DPPH radical scavenging ability and lightness of the rice stem extracts obtained from the 1st $(\diamond)$, 2nd $(\square)$, and 3 rd $(\triangle)$ treatments. The line indicates the relation obtained from the 1st extraction.

extracts. The yellowness $\left(b^{*}\right)$ and lightness $\left(L^{*}\right)$ of the extracts obtained using the subcritical ethanol and $75 \%(\mathrm{v} / \mathrm{v})$ ethanol showed a strong correlation $(\mathrm{R}=0.99)$. However, the redness $\left(\mathrm{a}^{*}\right)$ of the extracts showed no relevance to any other parameters.

In Fig. 5, the correlation between the lightness and DPPH radical scavenging ability of the extracts decreased with further treatment steps $(R=-0.96,-0.81$, and -0.64 for the 1 st, 2nd, and 3rd treatments, respectively). The negative correlation between the DPPH radical scavenging ability and lightness of the extracts would mean that the source of the radical scavenging ability were from black substances. It has been reported that the black liquor is obtained from the lignocellulosic materials treated in the organosolv process, which uses an organic solvent at elevated temperature and pressure [29-31]. During this process, the hemicellulose degradation products and lignin are solubilized into the black liquor. The hydrophobic black lignin can be separated from the black liquor by precipitation [32-34]. Several reports showed that the obtained black liquor possessed the antioxidative ability [35-37]. One of the sources of the DPPH radical scavenging ability may be related to the hydrophobic lignin, which promotes the blackness in rice stem extract. The color pigments, carotenoids and chlorophyll, in the rice stem may also be the sources of the extract radical scavenging ability. Carotenoids and chlorophyll, their derived and degraded substances, have been reported to possess a radical scavenging ability [38-43]. Furthermore, the products resulting from browning reactions, such as Maillard reactions and caramelization during subcritical water treatment, were reported to demonstrate a radical scavenging ability [44-46].

\section{Conclusions}

Different compounds were extracted by the subcritical water, ethanol and 75\% (v/v) ethanol. However, similar UV spectral patterns were obtained from the extracts obtained using the subcritical ethanol and $75 \%(\mathrm{v} / \mathrm{v})$ ethanol suggesting that the same compounds were extracted. Subcritical water would be 
the most effective subcritical solvent to loosen the lignocellular structure and to obtain carbohydrate compounds from the rice stem. The highest phenolic content was obtained using the subcritical ethanol after the cell wall structure was loosened by pre-treatment with subcritical water. However, the highest DPPH radical scavenging ability was obtained for the extracts obtained using the subcritical $75 \%(\mathrm{v} / \mathrm{v})$ ethanol in the 1 st treatment. The DPPH radical scavenging ability could be related to the blackness and yellowness of the extracts. The sources of the color could be the hydrophobic lignin, stem color pigments, and browning reaction products.

\section{Acknowledgement}

This study was partly financed by The Iijima Foundation.

\section{References}

[1] L. Dominguez-Escriba, M. Porcar, Biofuels Bioprod. Biorefin. 4 (2010) 154-159.

[2] L.K. Kadam, H. Forrest, W.A. Jacobson, Biomass Bioenerg. 18 (2000) 369-389.

[3] J.M. Lawther, R.C. Sun, W.B. Ind. Crops Prod. 5 (1996) 97-105.

[4] B. Xiao, X.F. Sun, R.C. Sun, Polym. Degrad. Stabil. 74 (2001) 307-319.

[5] B.E. Ricther, B.A. Jones, J.L. Ezzell, N.L. Porter, N. Avdolovic, C. Phol, Anal. Chem. 68 (1996) 10331039.

[6] W.L. Marshall, E.U. Franck, J. Phys. Chem. Ref. Data 10 (1981) 295-304.

[7] W. Wagner, A. Pruß, J. Phys. Chem. Ref. Data 31 (2002) 387-535.

[8] M.S.S. Curren, J.W. King, Anal. Chem. 73 (2001) 740745.

[9] J. Wiboonsirikul, Y. Kimura, M. Kadota, H. Morita, T. Tsuno, S. Adachi, J. Agric. Food Chem. 55 (2007) 87598765.

[10] N.E. Durling, O.J. Catchpole, J.B. Grey, R.F. Webby, K.A. Mitchel, L.Y. Foo, N.B. Perry, Food Chem. 101 (2007) 1417-1424.

[11] P. Khuwijitjaru, K. Watsanit, S. Adachi, J. Ind. Eng. Chem. 18 (2012) 225-229.

[12] W.J. Kim, B. Veriansyah, Y.W. Lee, J. Kim, J.D. Kim, Ind. Eng. Chem. 16 (2010) 425-430.

[13] D. Ambrose, C.H.S. Sprake, R. Townsend, J. Chem. Thermodyn. 7 (1975) 185-190.

[14] B.E. Poling, Fluid Phase Equilibria, 116 (1996) 102109.

[15] M. Dubois, K.A. Gilles, J.K. Hamilton, P.A. Rebers, F. Smith, Anal. Chem. 28 (1956) 350-356.

[16] S. Iqbal, M.I. Bhanger, F. Anwar, Food Chem. 93 (2005) 265-272.

[17] V.L. Singleton, J.A. Rossi, Am. J. Enol. Vitic. 16 (1965) 144-158.

[18] Y. Fujinami, A. Tai, I. Yamamoto, Chem. Pharm. Bull. 49 (2001) 642-644.

[19] S. Kumar, R. Gupta, Y.Y. Lee, R.B. Gupta, Bioresour.
Technol. 101 (2010) 1337-1347.

[20] L. Rohrschneider, Anal. Chem. 45 (1973) 1241-1247.

[21] L.R. Snyder, J. Chromatogr. 92 (1974) 223-230.

[22] I.M. Morrison IM, J. Sci. Food Agric. 23 (1971) 455-463.

[23] R.C. Sun, J. Tomkinson, X.F. Sun, N.J. Wang, Polymer 41 (2010) 8409-8417.

[24] T.J. Mabry, K.R. Markham, M.B. Thomas, The Systematic Identification of Flavonoids, Springer-Verlag, Berlin, 1970, pp. 41-164.

[25] S.N. Evstafiev, E.S. Fomina, E.A. Privalova, Russ. J. Bioorg. Chem. 38 (2012) 713-716.

[26] P.E. Savage, J.T. Henrikson, K.M. Benjamin, Chem. Rev. 99 (1999) 603-621.

[27] P. Daorattanachai, S. Namuangruk, N. Viriya-empikul, N. Laosiripojana, K. Faungnawakij, J. Ind. Eng. Chem. 18 (2012) 1893-1901.

[28] B. Tangkhavanich, T. Kobayashi, S. Adachi, Biosci. Biotechnol. Biochem. 76 (2012) 1146-1149.

[29] A. García, M. González Alriols, J. Labidi, Bioresour. Technol. 108 (2012) 155-161.

[30] L. Jimémez, M.J. de la Torre, J.L. Bonilla, J.L. Ferrer, Proc. Biochem. 33 (1998) 4111-4118.

[31] A.L. Macfarlane, R. Prestidge, M.M. Farid, J.J.J. Chen, Chem. Eng. J. 148 (2009) 15-19.

[32] H.B. Klinke, B.K. Ahring, A.S. Schmidt, A.B. Thomsen, Bioresour. Technol. 82 (2002)15-26.

[33] A. García, M. González Alriols, R. Llano-Ponte, J. Labidi, Bioresour. Technol. 102 (2011) 6326-6330.

[34] A. Rodríguez, A. Moral, R. Sánchez, L. Jiménez, Afinidad 66 (2009) 20-26.

[35] D. Amendola, D.M. De Faveri, I. Egües, L. Serrano, J. Labidi, G. Spigno, Bioresour. Technol. 107 (2012) 267-274.

[36] Q. Lu, W. Liu, L. Yang, Y. Zu, B. Zu, M. Zhu, Y. Zhang, X. Zhang, R. Zhang, Z. Sun, J. Huang, X. Zhang, W. Li, Food Chem. 131 (2012) 313-317.

[37] X. Pan, J.F. Kadla, K. Ehara, N. Gilkes, J.N. Saddler, J. Agric. Food Chem. 54 (2006) 5806-5813.

[38] Y. Endo, R. Usuki, T. Kaneda, J. Am. Oil Chem. Soc. 62 (1985) 1375-1378.

[39] M.G. Ferruzzi, V. Böhm, P.D. Courtney, S.J. Schwartz, Food Chem. Toxicol. 67 (2002) 2589-2595.

[40] M. Sato, I. Fujimoto, T. Sakai, T. Aimoto, R. Kimura, T. Murata, Chem. Pharm. Bull. 34 (1986) 2428-2434.

[41] S. Petrik, Z. Kádár, I. Márová, Bioresour. Technol. 133 (2013) 370-377.

[42] C. Prommuak, W. De-Eknamkul, A. Shotipruk, Sep. Purif. Technol. 62 (2008) 444-448.

[43] S. Siriamornpun, O. Kaisoon, N. Meeso, J. Funct. Food 4 (2012) 757-766.

[44] M.N. Maillard, C. Billaud, Y.N. Chow, C. Ordonaud, J. Nicolas, LWT-Food Sci. Technol. 40 (2007) 1434-1444.

[45] M. Plaza, M. Amigo-Benavent, M.D. del Castillo, E. Ibáñez, M. Herrero, Food Res. Int. 43 (2010) 1123-1129.

[46] M. Plaza, M. Amigo-Benavent, M.D. del Castillo, E. Ibáñez, M. Herrero, Food Res. Int. 43 (2010) 23412348. 